\title{
FEIRA DE CIÊNCIAS: UMA POSSIBILIDADE PARA A EDUCAÇÃO E DIVULGAÇÃO CIENTÍFICA
}

\author{
Science Fair: A Possibility for Education and Scientific Dissemination
}

\author{
Vanessa Candito ${ }^{1}$ \\ Karla Mendonça Menezes ${ }^{2}$ \\ Carolina Braz Carlan Rodrigues ${ }^{3}$
}

\begin{abstract}
Resumo: As Feiras de Ciências vêm se revelando como uma importante estratégia de valorização e estímulo à educação científica nas escolas, pois possuem características de atividades pedagógicas, interativas, educativas e culturais, com elevado potencial motivador do ensino e da prática científica no ambiente escolar, de modo a preparar os estudantes para uma prática reflexiva, a construção do conhecimento científico, e a difusão da cultura científica. Esse estudo analisou o desenvolvimento da II Feira de Ciências e Saberes: Semeando o Futuro, e sua relevância para a educação científica na Educação Básica. Esse evento ocorreu em uma escola pública, localizada no município de Santa Maria/RS, foi aberto ao público, e contou com a presença de estudantes e professores, além da comunidade escolar. Durante todo o terceiro trimestre letivo, os professores e estudantes estiveram envolvidos no planejamento, preparação e desenvolvimento dos estudos, que resultaram em um total de 130 educandos envolvidos e 40 trabalhos apresentados em forma de comunicação oral, organizados em blocos temáticos. $\mathrm{O}$ evento demonstrou ser um importante meio para a divulgação científica ao permitir a socialização do conhecimento científico entre os estudantes e o público em geral. Assim, esse estudo aponta a relevância do desenvolvimento de feiras de ciências nas escolas, promovendo a compreensão científica no estudante, a construção de competências e um importante momento de divulgação científica.
\end{abstract}

Palavras-chave: Educação Básica. Feiras de Ciências. Investigação Científica. Divulgação Científica.

Abstract: Science Fairs are proving to be an important strategy for valuing and stimulating scientific education in schools, as they have characteristics of pedagogical, interactive, educational, and cultural activities, with a high motivating potential for teaching and scientific practice in the school environment, in a way to prepare students for reflective practice, the construction of scientific knowledge, and the diffusion of scientific culture. This study analyzed the development of the II Science and Knowledge Fair: Sowing the Future, and its relevance as a purpose for science education in Basic Education. The fair took place in a public school,

\footnotetext{
${ }^{1}$ Doutoranda em Educação em Ciências e Mestra em Educação em Ciências pela Universidade Federal do Rio Grande do Sul. Especialista em Educação Ambiental pela Universidade Federal de Santa Maria e Especialista em Conservação da Biodiversidade pela Universidade Regional Integrada do Alto Uruguai e das Missões. ORCID: http://orcid.org/0000-0003-4663-9590. E-mail: vanecandito@gmail.com.

${ }^{2}$ Doutora em Educação em Ciências pela Universidade Federal de Santa Maria. ORCID: http://orcid.org/00000002-7482-0648. E-mail: karlam.ef@ gmail.com.

${ }^{3}$ Doutora em Educação em Ciências: Química da Vida e Saúde pela Universidade Federal de Santa Maria. ORCID: http://orcid.org/0000-0001-7115-0987. E-mail: carolinabcarlan@gmail.com.
} 
located in the municipality of Santa Maria-RS, and was an event open to the public, which was attended by students and teachers, in addition to the school community. Throughout the third academic quarter, teachers and students were involved in the planning, preparation of the work, and development of the study, which resulted in a total of 130 students involved and 40 papers presented in the form of oral communication based on thematic blocks. The event proved to be a means for scientific dissemination by allowing the socialization of scientific knowledge among students and the general public. Thus, this study points to the importance of promoting science fairs in schools, as a way of scientific understanding in students, building skills, and the importance of the fair as a space for scientific dissemination.

Keywords: Basic Education. Science Fair. Scientific research. Scientific disclosure.

\section{Introdução}

As instituições escolares têm um papel relevante na difusão da cultura científica, pois o conhecimento e os valores da cidadania são imprescindíveis para a compreensão da vida cotidiana, desenvolvimento do pensamento autônomo e inserção crítica na sociedade (BRASIL, 2006). Constituindo-se como um lugar de acesso e produção de conhecimento, a escola desempenha uma função relevante na medida em que introduz os escolares no universo da investigação e da divulgação científica (CANDITO; RODRIGUES; MENEZES, 2020).

Dentre as atividades educativas responsáveis em desenvolver no educando essas potencialidades, a realização das Feiras de Ciências (FC) constituem-se em um recurso importante na Educação Básica, apresentando-se como um meio propício ao fomento da cultura científica. Além disso, facilitam a popularização do conhecimento construído, pois inovam o processo de ensino e aprendizagem, vão além da sala de aula, e incentivam o espírito científico.

Candito, Rodrigues e Menezes (2020) ainda frisam que a iniciativa da instituição escolar em desenvolver atividades como feira de ciências aproxima os docentes e discentes das atividades científicas, contribuiu e desenvolve a aprendizagem do estudante, despertando a criatividade e a capacidade de construir conhecimentos científicos.

Essas experiências possibilitam o desenvolvimento da criatividade e da capacidade inventiva, despertam vocações e incentivam a pesquisa na escola. As feiras de ciências promovem ainda, a participação de toda a comunidade escolar em torno de um projeto pedagógico que integra não só as disciplinas, mas todas as áreas de conhecimento. Além disso, demonstram uma excelente oportunidade para que a escola transponha seu espaço físico e estabeleça um contato direto com a comunidade local, promovendo um diálogo educativo no âmbito da sociedade (BRASIL, 2006).

A nomenclatura para a amostra das atividades científicas desenvolvidas no âmbito escolar não é única. Segundo o Programa Nacional de Apoio às Feiras de Ciências da Educação Básica (FENACEB), há muitas maneiras de denominar o evento, tais como: "Feira de Criatividade Estudantil", "Mostra de Talentos Estudantis", "Feira de Ciências, Artes e Criatividade", "Mostra da Produção Estudantil", "Feira de Múltiplos Talentos", "O que produzimos em nossa escola", "Feira de Ciências e Tecnologia", "Mostra da Produção Científica, Tecnológica e Literária", "Feira de Conhecimentos", "Feira de Ciência e Cultura" (BRASIL, 2006). Entendendo a aproximação conceitual dessas terminologias, esse texto utilizará os termos feira de ciências, feiras de ciências ou a expressão lacônica FC. 
É importante ressaltar a relevância das feiras de ciências para a divulgação científica nas escolas, porém, os estudos dedicados a esse tema permanecem incipientes. Dentre os poucos estudos encontrados na literatura nacional, destaca-se um levantamento realizado por Gallon et al. (2017) sobre os trabalhos publicados nas edições do Encontro Nacional de Pesquisa em Educação em Ciências (ENPEC) no período de 1997 a 2015, onde foram identificados apenas 24 trabalhos direcionados às Feiras de Ciências.

Em outra revisão, Pereira (2019) encontrou apenas seis artigos, em cinco periódicos da área de ensino. Scaglioni et al. (2020) investigaram as produções sobre Feiras de Ciências com base nas publicações nacionais de dissertações e teses disponíveis no Catálogo de Teses e Dissertações da Capes (BTC), na Biblioteca Digital Brasileira de Teses e Dissertações (BDTD) e no Portal Brasileiro de Publicações Científicas em Acesso Aberto (OASISBR), no período de 2010 a 2019, e identificaram 124 títulos, distribuídos entre teses e dissertações.

Souza (2015) afirma que as feiras de ciências se constituem como uma ferramenta educacional, e defende que os trabalhos podem estar conectados a múltiplas áreas do conhecimento, servindo assim, como uma estratégia para promover o Ensino das Ciências. Mezzari, Frota e Martins (2011) afirmam que, além de promover uma aprendizagem significativa, a participação dos educandos nas feiras de ciências propicia o contato destes com toda a comunidade escolar, desenvolvendo atividades culturais, tecnológicas e sociais e, como consequência desta experiência, formam-se também socialmente, ambientalmente e moralmente.

O recente estudo de Candito, Rodrigues e Menezes (2020) investigou a percepção dos docentes em relação às contribuições de uma experiência da feira de ciências para a educação científica na Educação Básica. As autoras concluíram que a Feira se apresentou como uma prática pedagógica eficiente ao possibilitar a integração teoria-prática dos conteúdos curriculares, além de aproximar os estudantes à busca e construção do conhecimento, e articulação de valores, como o trabalho coletivo e o respeito ao próximo, evidenciando o papel da escola na difusão da cultura científica.

A Base Nacional Comum Curricular (BNCC) ressalta o compromisso do ensino com o desenvolvimento do letramento científico, que envolve a capacidade de compreender e interpretar o mundo (natural, social e tecnológico), além de transformá-lo com base nos aportes teóricos e processuais das ciências (BRASIL, 2018).

Desse modo, a realização de FC na escola proporciona a produção de novos conhecimentos, por meio da efetivação de projetos que envolvem pesquisas científicas, e tem se mostrado uma importante metodologia no desenvolvimento de novas competências nos estudantes (SANTOS, 2012). Uma vez que, através da troca desenvolvida entre educandos, juntamente com professores, as feiras de ciências permitem desenvolver e expressar algumas das competências estabelecidas pela BNCC do Ensino Fundamental e Ensino Médio. Tal documento define conhecimentos essenciais para a Educação Básica, estabelecendo habilidades e competências em cada etapa do ensino (BRASIL, 2018).

Para tanto, as feiras de ciências possuem características de atividades pedagógicas, interativas, educativas e culturais, com elevado potencial motivador do ensino e da prática científica no ambiente escolar. Nesse sentido, as FC têm como objetivo incentivar a investigação científica nas escolas. Pereira et al. (2000) entendem que os objetivos da realização de Feiras de Ciências configuram-se como estratégias de ensino capazes de promover a autonomia dos estudantes na construção de trabalhos investigativos, propiciando um conjunto de experiências interdisciplinares. Além do empreendimento social-científico, que proporciona 
aos estudantes expor os trabalhos por eles realizados à comunidade, possibilitando um intercâmbio de informações (PEREIRA et al., 2000).

Desse modo, tanto para estudantes e professores quanto para a comunidade em geral, as feiras vêm constituindo uma oportunidade de aprendizagem e de entendimento sobre as etapas de construção do conhecimento científico. E, a partir dessa iniciativa, que os professores e os educandos possam se aproximar mais das atividades científicas no meio escolar, contribuindo decisivamente no desenvolvimento de sua autonomia intelectual e despertando a criatividade e a capacidade de construir conhecimento.

Em eventos como a FC, segundo Hartmann e Zimmermann (2009), os estudantes vivenciam a iniciação científica de forma prática, buscando soluções técnicas e metodológicas para problemas. Sendo assim, os processos de construção do conhecimento se tornam mais significativos. Pereira et al. (2000) sinalizam, que a FC visa agregar um conjunto de situações e experiências que incentivam o desenvolvimento das atividades científicas e da capacidade do estudante para buscar e organizar os materiais, elaborar registros e fazer a apresentação dos dados obtidos. Na visão de Lima (2004), as Feiras de Ciências despertam a curiosidade e o interesse do estudante, da criatividade e mobilização do professor, da vida e do sentido social da escola.

Assim, as feiras de ciências têm colocado os estudantes da Educação Básica no papel de protagonistas na construção de seu conhecimento, tendo os professores como orientadores e mediadores do processo de ensino-aprendizagem. Corroborando com Mancuso e Leite Filho (2006), os quais concluíram que os trabalhos apresentados nas FC devem ser realizados pelos estudantes, mediados por um ou mais professores.

Dessa forma, a interação do estudante com o professor alcança objetivos comuns, uma vez que o estudante tem a chance de agir de forma ativa, interagindo com o objeto de pesquisa e desenvolvendo aptidões para o trabalho científico, ou seja, investiga, explora, registra, argumenta, conclui e compartilha conhecimentos. Enquanto o professor torna-se parceiro de trabalho, despertando no educando a vontade de também produzir, ao passo em que promovem o processo de pesquisa. Assim, no dia do evento, os estudantes têm a oportunidade de apresentar seus trabalhos ao público, expressando seus conhecimentos e construindo valores, sendo assim de grande valia para uma aprendizagem social e cognitiva (NUNES et al., 2016).

Com base nesse escopo teórico, percebe-se o potencial das feiras de ciências em contextualizar a realidade dos estudantes e permitir a construção coletiva do conhecimento científico. De tal modo, esse estudo se dedica a analisar o processo de estruturação e desenvolvimento de uma Feira de Ciências, de uma escola estadual de Santa Maria/RS, e sua relevância para a educação científica na Educação Básica.

\section{A Feiras de Ciências e Saberes}

A segunda edição da Feira de Ciências e Saberes foi norteada pela temática "Semeando o Futuro", em conformidade com o Projeto Político Pedagógico (PPP) ${ }^{4}$ da instituição escolar, que no ano de 2019 esteve orientado pelo Tema Integrador: "Meu lugar", denominando-se então

\footnotetext{
${ }^{4}$ Previsto na Lei de Diretrizes e Bases da Educação Nacional (LDB) 1996, o Projeto Político Pedagógico define e organiza as atividades e projetos educativos necessários ao processo de ensino-aprendizagem, reunindo propostas de ações a serem executadas durante determinado período de tempo, e considera a escola como um espaço de formação de cidadãos conscientes, responsáveis e críticos.
} 
de II Feira de Ciências e Saberes: Semeando o Futuro. O evento ocorreu no final do ano letivo de 2019, e teve como cenário uma escola estadual pública, vinculada à $8^{a}$ Coordenadoria Regional de Educação do estado do Rio Grande do Sul.

Em consonância com os documentos balizadores da instituição escolar, a feira de ciências teve por finalidade criar um espaço de vivência do estudante na busca pela autonomia na construção do seu conhecimento, ressignificar a relação de ensino-aprendizagem, integrar a escola e a sociedade, e desenvolver as habilidades necessárias para trabalhar em grupo, bem como resolver problemas através da pesquisa e da integração com o pequeno e grande grupo, possibilitando o exercício da cidadania.

A escola, na qual realizou-se a FC, localiza-se na periferia do município de Santa Maria/RS, e oferta os níveis de Ensino Fundamental e Médio, atuando nos três turnos de atendimento. No ano de 2019, estiveram matriculados 176 estudantes nos anos iniciais, e 225 nos finais do Ensino Fundamental, 101 escolares no Ensino Médio e 25 estudantes na Educação Especial.

Conforme referido anteriormente, a realização da Feira de Ciências e Saberes esteve prevista dentre as atividades pedagógicas anuais da instituição escolar, e fundamentada no PPP (2019). Assim, o planejamento e a elaboração prenunciados no calendário do ano letivo fizeram com os que docentes organizassem as propostas, tornando-a uma atividade inserida no currículo.

Conforme citado no PPP (2019), a condução de atividades extraclasse, como: combate ao analfabetismo, educação para a saúde, educação fiscal e ambiental, atividades de aprendizagens tecnológicas, atividades culturais e esportivas, proporcionam projetos escolares diversificados, que reascendam a paixão pelo estudo, a participação dos estudantes como agentes do seu crescimento pessoal e intelectual, bem como autonomia e valorização do aprendizado coletivo.

Ainda de acordo com o PPP da escola, a metodologia a ser trabalhada no Ensino Fundamental e Médio (nas diferentes áreas do conhecimento) está embasada na interação entre o educando e o objeto do conhecimento, mediada pela intervenção pedagógica e didática do professor, oportunizando a aprendizagem significativa. Dessa forma, considera a pesquisa pedagogicamente estruturada, para a construção de novos conhecimentos e a formação de sujeitos pesquisadores, críticos e reflexivos no cotidiano da escola, oportunizando a apropriação adequada da realidade, projetando possibilidades de intervenção potencializada pela investigação e pela responsabilidade ética. Além disso, a pesquisa oportuniza ao estudante a exploração de seus interesses e o exercício da autonomia, ao formular e experimentar projetos de vida e de sociedade.

Portanto, amparado pelos documentos da escola, a proposta do desenvolvimento da FC, visa desenvolver habilidades e competências nos estudantes, favorecendo a construção coletiva do conhecimento científico, integração com a comunidade a partir da divulgação dos trabalhos desenvolvidos, e a relevância do PPP como um orientador do trabalho pedagógico.

\section{Percurso Metodológico}

Esse estudo se dedica a analisar o desenvolvimento da II Feira de Ciências e Saberes: Semeando o Futuro, desenvolvida em uma escola da rede pública estadual do Rio Grande do Sul, e adota uma natureza qualitativa, com abordagem descritiva observacional. Conforme Gil (2008), as pesquisas descritivas têm como objetivo primordial a descrição das características 
de determinada população ou fenômeno ou, então, o estabelecimento de relações entre variáveis, além de que uma de suas características mais significativas está na utilização da observação sistemática.

Inicialmente esse estudo partiu-se da análise documental do Projeto Político Pedagógico da instituição escolar e do Regulamento da II Feira de Ciências e Saberes: Semeando o Futuro. Em um segundo momento foram realizadas observações diretas das atividades de planejamento e organização dos trabalhos. No terceiro momento, foi observado o desenvolvimento das atividades no dia do evento, e por fim, deu-se a análise integrada das interações entre os documentos orientadores e as ações que perpassaram o planejamento e execução do evento.

Dessa forma, foi possível identificar as etapas de realização da Feira de Ciências Saberes, conforme a descrição do quadro 1.

Quadro 1 - Etapas de realização da II Feira de Ciências E Saberes: Semeando o Futuro
\begin{tabular}{|l|l|}
\hline Etapa 1 & $\begin{array}{l}\text { Organização geral da Feira de Ciências e Saberes pela Coordenação } \\
\text { pedagógica }\end{array}$ \\
\hline Etapa 2 & $\begin{array}{l}\text { Formação dos grupos e inscrições dos estudantes em forma de } \\
\text { resumo expandido }\end{array}$ \\
\hline Etapa 3 & $\begin{array}{l}\text { Organização dos trabalhos pelos estudantes e professores } \\
\text { orientadores abrangendo blocos temáticos }\end{array}$ \\
\hline Etapa 4 & $\begin{array}{l}\text { Orientações dos trabalhos, mediados pelos professores orientadores, } \\
\text { juntamente com pesquisadoras de um grupo de estudos de uma } \\
\text { Universidade Pública Federal }\end{array}$ \\
\hline Etapa 5 & $\begin{array}{l}\text { Desenvolvimento da Feira de Ciências e Saberes e apresentação dos } \\
\text { trabalhos }\end{array}$ \\
\hline Etapa 6 & Avaliação dos trabalhos apresentados \\
\hline
\end{tabular}
Fonte: Elaborado pelas autoras (2021).

Enquanto recurso metodológico diferenciado, capaz de promover o processo de ensino e aprendizagem de forma crítica, autônoma e prazerosa, contemplando a comunidade escolar, a II Feira de Ciências e Saberes: Semeando o Futuro, foi realizada no dia 09 de novembro de 2019, em um sábado pela manhã, e ocorreu nas dependências da escola, onde foram utilizadas as salas de aula e os espaços de grande circulação para receber os estudantes, professores e a comunidade em geral.

O evento foi aberto ao público, e contou com divulgação interna entre os estudantes e professores, e por meio das redes sociais da escola estendeu-se o convite à comunidade, enfatizando a importância da ciência na construção de saberes. Dessa forma, as feiras de ciências são uma importante ferramenta de integração da escola com a comunidade, pois elas dão oportunidade para os estudantes demonstrarem, por meio de seus projetos, seu conhecimento científico e sua criatividade.

Destarte, o evento afirma as intenções do PPP, o qual prevê uma maior integração da comunidade escolar nas atividades previstas no calendário escolar, e a ampliação da qualidade educacional, por meio de um ensino organizado, de maneira que os envolvidos nas ações educativas possam perceberem-se sujeitos, reconhecendo o seu papel na comunidade e serem capazes de sugerir e intervir nas decisões do grupo de forma organizada, ética e responsável.

Privilegiando o trabalho colaborativo e o compartilhamento de ideias e experiências, todos os estudantes foram encorajados a participar da feira de ciências como autores e apresentadores. Para os estudantes do Ensino Médio, a elaboração e apresentação dos trabalhos integrou parte da avaliação cumulativa do processo da aprendizagem, e privilegiou o trabalho 
em grupo e a troca de ideias e experiências. Os estudantes do $9^{\circ}$ ano do Ensino Fundamental participaram como ouvintes, e deveriam apresentar um Relato de Observação dos trabalhos da feira, e os demais escolares tiveram a participação facultativa.

Para a inscrição na FC, os participantes deveriam submeter um resumo expandido (avaliação inicial dos trabalhos), que seguia uma padronização específica, de acordo com normas do regimento da feira, e deveriam ser enviados para o e-mail da equipe organizadora.

As temáticas apresentadas envolveram as cinco áreas do conhecimento do Ensino Fundamental e quatro áreas do conhecimento do Ensino Médio (Linguagens, Ciências Humanas, Ciências da Natureza, Matemática e Ensino Religioso), abrangendo os blocos: Tecnologias, Empreendedorismo, Meio Ambiente, Humanidades, Saúde, Sustentabilidade, Comunicação e Política. Dessa forma, os estudantes foram incentivados pela equipe organizadora a desenvolver projetos que contemplassem diferentes Áreas do Conhecimento.

A Feira de Ciências e Saberes teve um total de 40 trabalhos inscritos, sendo que 130 educandos integraram os grupos para apresentação oral. Cada grupo, composto de três ou quatro estudantes, foi orientado por um docente, que tinha a responsabilidade de conduzir os estudantes no desenvolvimento do trabalho inicial (resumo expandido) e apontar os aspectos a serem melhorados; possíveis correções propostas em datas anteriores a avaliação; indicando sugestões para a melhoria da estrutura do trabalho e a apresentação no dia do evento.

Além do mais, os estudantes também contaram com o suporte de pesquisadoras do Grupo de Estudos em Nutrição, Saúde e Qualidade de Vida /GENSQ da Universidade Federal de Santa Maria/RS. O referido grupo de estudos integra uma proposta de trabalho participativo e colaborativo, já consolidada com a instituição escolar desde 2011. Para a Feira de Ciências e Saberes, as pesquisadoras colaboraram com as ideias para a construção dos projetos, além de integrarem parte da Comissão de Avaliação, no dia do evento.

Durante todo o terceiro trimestre letivo, os professores e estudantes estiveram envolvidos no planejamento, preparação e desenvolvimento do trabalho. As tarefas foram divididas entre pesquisas, levantamento de recursos e materiais a serem utilizados, planejamento e elaboração para a apresentação, envolvendo cenário, cartazes, e outros recursos tecnológicos.

Conforme o regimento da FC, os trabalhos foram exibidos em forma de comunicação oral, e as apresentações organizadas com base nos blocos temáticos. As falas deveriam ser divididas entre todos os integrantes da equipe, seguindo critérios de organização e utilizandose de todos os recursos que seriam necessários e utilizados na apresentação final no dia da feira.

\section{II Feira de Ciências e Saberes: a construção do pensamento científico e da divulgação científica}

Segundo Oaigen, Bernard e Souza (2013), as feiras de ciências podem contribuir para despertar no estudante o interesse em conhecer melhor os diversos aspectos de sua realidade (social, econômica, política, entre outros) por meio de temas que o incite a observar e investigar de forma científica o mundo que está a sua volta, estimulando que o mesmo aprenda, desde cedo, a planejar e executar experiências e projetos, adquirindo assim, confiança e uma visão crítica e criativa frente à resolução de problemas.

Nessa perspectiva, o desenvolvimento das temáticas foi essencial ao trabalho, pois demonstrou atratividade aos estudantes, por meio de um tema que eles se identificaram, além 
de estar inserido no currículo escolar e no contexto da escola, para que a comunidade também utilize dos benefícios advindos da FC (JUNIOR et al., 2019).

Além disso, Candito, Rodrigues e Menezes (2020) relatam que o desenvolvimento do projeto para a Feira de Ciências contribuiu para o conhecimento e aprendizagem do estudante. No referido estudo, as docentes investigadas apontaram que os saberes se relacionam com o planejamento e organização da feira, e influenciam nas relações pessoais e na interação dos estudantes e dos professores, tornando-se facilitadores para a vivência e a socialização dos estudantes. Assim, o contato entre os estudantes para a realização da FC propicia o intercâmbio de saberes, e interfere na sua formação científica por meio de trocas e experiências.

Santos (2012) pontua que a apresentação pública dos trabalhos pelos estudantes, inerente aos projetos de feiras de ciências, tende a contribuir para o aumento do potencial criativo dos estudantes, além da intensificação das interações sociais. $\mathrm{O}$ autor esclarece que a apresentação pública também favorece o desenvolvimento cognitivo, o exercício da cooperação e a construção da autonomia de professores e estudantes envolvidos no trabalho. Assim, durante as observações, foi possível perceber o engajamento dos estudantes com os projetos. Alguns se sentiram envergonhados, outros ansiosos, e também empolgados com a oportunidade de expressar seu trabalho de forma diferenciada.

Em um estudo semelhante, Junior et al. (2019) avaliaram como os projetos foram elaborados para a Feira de Ciências Estadual de Roraima, enquanto espaço de divulgação científica. Na realização dos projetos, os estudantes foram os responsáveis pela escolha do tema a ser trabalhado na pesquisa e durante esse processo, o professor foi responsável pelas orientações. Os autores relatam que os educandos que participaram do desenvolvimento do projeto e das apresentações se mostraram motivados e criativos.

Nesse contexto, as feiras de ciências podem favorecer a avaliação formativa das escolas. Conforme Villas Boas (2008), a avaliação formativa ocorre nas interações do estudante com o professor e com os outros educandos, possibilitando adaptações contínuas enquanto se desenvolve a aprendizagem.

Lima (2011) refere que as feiras são um exercício de avaliação não só do próprio trabalho, mas também do trabalho do outro, dos instrumentos e métodos utilizados e da infraestrutura do próprio evento. Assim, no dia da apresentação, os trabalhos foram analisados por uma Comissão de Avaliação, composta por professores da escola e pesquisadoras do grupo de estudos. Os avaliadores observaram as apresentações e continham uma ficha para anotações, na qual deveria ser atribuída notas de 0 a 10 pontos em distintos requisitos.

Seguindo o regimento da FC e os critérios de avaliação do trimestre, a avaliação final dos estudantes se deu pela elaboração do resumo expandido, organização do espaço, participação no desenvolvimento do trabalho, coerência com o bloco temático, pontualidade e comprometimento e por fim, a apresentação do trabalho.

Como citado anteriormente, os educandos do $9^{\circ}$ Ano do Ensino Fundamental participaram como ouvintes, e dessa forma, visitaram as apresentações que aconteciam nas salas de aula e os espaços de grande circulação da escola. Com isso, apresentaram um Relato de Observação da FC, seguindo critérios avaliativos como: estética do texto, correção gramatical e organização do texto.

Pode-se levar em consideração que a Feira de Ciências e Saberes vem ao encontro do que citam Oaigen, Bernard e Souza (2013), ao tratar os projetos das feiras de ciências como um produto a ser obtido nos trabalhos em sala de aula e realizados pelos educandos com a orientação e mediação do professor, onde, por meio de um processo investigatório, é possível 
definirem: a sondagem de aptidões, por meio da livre escolha do tema investigatório; planejamento e execução de atividades por parte do educando; a preparação para o trabalho, por meio do treinamento de elaboração de instrumentos e coleta de dados; e integração do indivíduo na comunidade, por meio das apresentações dos projetos.

Os resultados desse estudo se assemelham às ações do estudo de Victorio, Miranda e Marques (2020), que comentam que dessa forma é possível identificar os efeitos da avaliação formativa, durante todo o processo de construção da feira, através de ações como: o desempenho dos educandos durante o desenvolvimento dos seus trabalhos em equipe; a troca de informações para a elaboração do resumo, e a colaboração do professor avaliador.

Lima (2004) frisa a feira de ciências como um espaço de trocas e amplificação de aprendizagens, pois, ao apresentar um trabalho, os educandos têm a oportunidade de ouvir comentários e questões sobre o que produziram, encontrando outras perspectivas ou ângulos de visão. Assim, cabe salientar que muitos dos estudantes não haviam participado de uma feira de ciências, observando-se assim, que foi possível a disseminação cultural e, sobretudo, a divulgação científica.

Ao participar de uma Feira de Ciências, o estudante torna-se sujeito ativo da construção do seu aprendizado, desenvolve habilidades pessoais, como aprender a trabalhar em equipe, a comunicar-se, aceitar as ideias, respeito a diversidade existente entre as pessoas, o respeito ao social e aos outros (NUNES et al., 2016). Além da capacidade de os estudantes planejarem, executarem e relatarem criticamente suas investigações científicas, indo ao encontro das competências e habilidades da BNCC. Nessa perspectiva, ressalta-se que a Feira de Ciências e Saberes vem ao encontro dos fundamentos da BNCC ao relatar em suas competências gerais que é necessário:

\footnotetext{
Exercitar a curiosidade intelectual e recorrer à abordagem própria das ciências, incluindo a investigação, a reflexão, a análise crítica, a imaginação e a criatividade, para investigar causas, elaborar e testar hipóteses, formular e resolver problemas e criar soluções (inclusive tecnológicas) com base nos conhecimentos das diferentes áreas. (BRASIL, 2018, p. 09).
}

Desse modo, privilegia-se as práticas que concebem o estudante como sujeito do seu próprio processo de aprendizagem, construindo relações com o conhecimento de modo autônomo (FREIRE, 2000). O autor defende que a educação deve criar um ambiente de possibilidades para a construção do conhecimento, que não se dá pelo mero recebimento passivo de informações.

Dessa forma, a realização de projetos que busquem incentivar a promoção das feiras de ciências na Educação Básica se torna essencial para o envolvimento e a articulação entre as escolas e a educação científica, como forma de construir o pensamento científico e a divulgação científica, e contribuir no ensino-aprendizagem, nas avaliações desses processos, na integração da comunidade nas atividades escolares e, sobretudo, na interação dos educandos com as propostas didáticas.

\section{Considerações Finais}

As feiras de ciências vêm se revelando como uma importante estratégia de valorização e estímulo à educação científica nas escolas. Tende a valorizar as atividades pedagógicas desenvolvidas pelos professores e estudantes, dando oportunidade para o envolvimento com 
apresentações de trabalhos, interesse pela pesquisa, socialização do conhecimento, troca de informações, além de promover a interação entre os participantes e a comunidade escolar, e valorizar a escola pública como espaço de divulgação da ciência.

A II Feira de Ciências e Saberes: Semeando o Futuro demonstrou ser um importante instrumento para a divulgação científica ao permitir a socialização do conhecimento científico entre os estudantes e o público em geral. Dessa forma, ressalta-se o plano de ação da escola, com a intenção em dar continuidade a promoção da FC com o comprometimento para com os estudantes, tornando-os proativos no processo de ensino.

Por fim, ao evidenciar a importância das feiras de ciências nas escolas, ensejamos a necessidade de que mais trabalhos nesse escopo sejam realizados, com vistas a fomentar essa estratégia de ensino para que se torne mais frequentes e efetiva na compreensão científica do estudante, promovendo a construção de competências e a importância da FC, enfatizando também, a sua relevância enquanto espaço de divulgação científica.

\section{Referências}

BRASIL. Programa Nacional de Apoio às Feiras de Ciências da Educação Básica FENACEB. Brasília, DF: Ministério da Educação/Secretaria de Educação Básica, 2006.

Disponível em: http://portal.mec.gov.br/seb/arquivos/pdf/EnsMed/fenaceb.pdf. Acesso em: 15 abr. 2021.

BRASIL. Base Nacional Comum Curricular. Brasília: MEC, 2018.

CANDITO, V.; RODRIGUES, B. C. C.; MENEZES, M. K. Feira de Ciências e Saberes: um olhar dos docentes para as contribuições da educação científica na educação básica. Olhares \& Trilhas, Uberlândia, v. 22, n. 3, 2020.

FREIRE, P. Pedagogia da autonomia: saberes necessários à prática educativa. 50. ed. Rio de Janeiro: Paz e Terra, 2000.

GALLON, M. S.; ROCHA FILHO, J. B.; NASCIMENTO, S. S. Feiras de ciências nos ENPECs (1997-2015): identificando tendências e traçando possibilidades. In: ENCONTRO NACIONAL DE PESQUISA EM EDUCAÇÃO EM CIÊNCIAS, 11., 2017, Florianópolis. Anais [...]. Florianópolis: UFSC, 2017. Disponível em: http://abrapecnet.org.br/enpec/xienpec/anais/resumos/R1722-1.pdf. Acesso em: 15 abr. 2021.

GIL, A. C. Como elaborar projetos de pesquisa. 4. ed. São Paulo: Atlas, 2008.

HARTMANN, M. A.; ZIMMERMANN, E. Feira de Ciências: a interdisciplinaridade e a contextualização em produções de estudantes de Ensino Médio. In: ENCONTRO NACIONAL DE PESQUISA EM EDUCAÇÃO EM CIÊNCIAS, 7., 2009, Florianópolis. Anais [...]. Florianópolis: ABRAPEC, 2009.

JUNIOR et al. Avaliação da Feira de Ciências de Roraima enquanto espaço de Divulgação Científica. Revista Insignare Scientia - RIS, v. 2, n. 1, p. 75-90, 20 maio 2019.

LIMA, M. E. C. Feira de Ciências: a produção escolar veiculada e o desejo de conhecer no aluno. Recife: Espaço Ciência, 2004. 
LIMA, M. E. C. Feiras de ciências: o prazer de produzir e comunicar. In: PAVÃO, A. C.; FREITAS, D. (Org.). Quanta ciência há no ensino de ciências? São Carlos: UFSCar, 2011.

MANCUSO, R; LEITE FILHO, I. Feiras de Ciências no Brasil: Uma trajetória de quatro décadas. In: Programa Nacional de Apoio às Feiras de Ciências da Educação Básica FENACEB. Brasília, DF: Ministério da Educação/Secretaria de Educação Básica, 2006.

MEZZARI, S.; FROTA, P. R. de O.; MARTINS, M. da C. Feiras multidisciplinares e o ensino de ciências. Revista Eletrônica de Investigação e Docência, n. monográfico, p. 107119, 2011.

NUNES, S. M. T. et al. As Feiras de Ciências da UFG/RC: construindo conhecimentos interdisciplinares de forma prazerosa. REDEQUIM, v. 2, n. 2, set. 2016.

OAIGEN, E. R.; BERNARD, T.; SOUZA, C. A. Avaliação do evento feiras de ciências: aspectos científicos, educacionais, socioculturais e ambientais. Revista Destaques Acadêmicos, Edição especial, 2013.

PEREIRA, A, B.; OAIGEN, E. R.; HERING.G. Feira de Ciências. Canoas: Ulbra, 2000.

PEREIRA, B. A. I. A presença de indicadores da Alfabetização Científica em trabalhos de Feiras de Ciências. Dissertação (Mestrado) - Programa de Pós-Graduação em Mestrado Profissional em Ensino de Ciências, Universidade Federal do Pampa, Bagé, 2019.

SANTOS. A. B. Feiras de Ciência: Um incentivo para desenvolvimento da cultura científica. Rev. Ciênc. Ext. v.8, n.2, p.155-166, 2012.

SCAGLIONI, C. G. et al. Estudo de teses e dissertações nacionais sobre Feiras de Ciências: mapeamento dos elementos que envolvem uma Feira de Ciências e suas interligações. Revista Educar Mais, v. 4, n. 3, 2020.

SOUZA, M. do S. M. de. As Feiras de Ciências em Roraima no período de 1986 a 2008: contribuição para iniciação à educação científica. 2015. 169f. Dissertação (Mestrado Profissional em Ensino de Ciências) - Universidade Estadual de Roraima, Boa Vista, RR, 2015.

VICTORIO, S. da S.; MIRANDA, M. C. R.; MARQUES, R. N. A importância da avaliação formativa em feiras de ciências. Revista on line de Política e Gestão Educacional, Araraquara, v. 24, n. 1, p. 210-223, jan./abr., 2020.

VILLAS BOAS, B. M. F. Virando a escola do avesso por meio da avaliação. Campinas: Papirus, 2008.

Recebido em agosto de 2021.

Aprovado em outubro de 2021. 